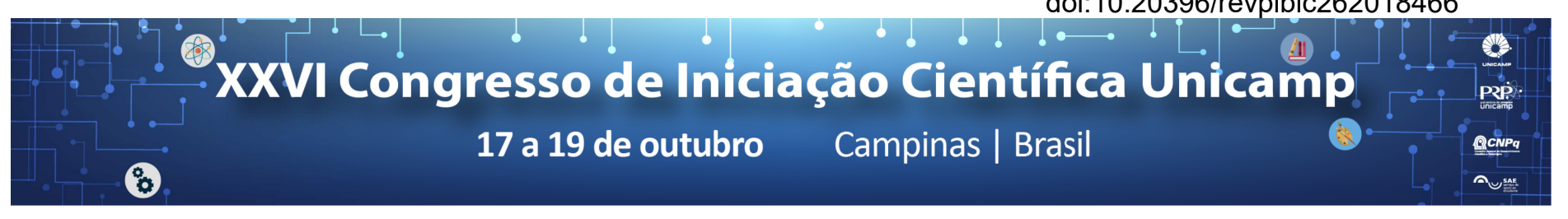

\title{
Análise Dinâmica e do Limiar de Estabilidade de Sistemas Rotativos com Mancais Hidrodinâmicos e Amortecedores do tipo "Squeeze Film"
}

\author{
Francisco N. S. Franco*, Gregory B. Daniel.
}

\begin{abstract}
Resumo
Atualmente, rotores são muito utilizados na indústria em várias aplicações de engenharia. Compõem desde compressores elétricos domésticos a turbinas eólicas de grande escala, sendo o principal mecanismo de transmissão de força em máquinas de várias escalas. A análise dinâmica de máquinas rotativas é uma tarefa muito complexa, pois envolve diversos parâmetros. Diante disso, este projeto de iniciação científica teve por objetivo analisar o comportamento dinâmico de sistemas rotativos considerando diferentes tipos de mancais lubrificados e amortecedores do tipo "squeeze film", de forma a verificar suas influências tanto na amplitude de vibração como no limiar de instabilidade. As análises dinâmicas foram desenvolvidas no domínio da frequência, com ênfase na Função Resposta ao Desbalanceamento (FRD), Diagrama de Campbell e Decremento logarítmico (análise de autovalor). Para isso, o eixo rotativo foi modelado através do método dos elementos finitos (MEF), considerando os elementos de viga de Timoshenko e os elementos de discos. Já os mancais e o amortecedor do tipo "squeeze film" são introduzidos no sistema através de coeficientes equivalentes dinâmicos (rigidez, amortecimento e inércia). Portanto, ao fim desse projeto foi possível analisar a influência dos mancais e do amortecedor no comportamento dinâmico do rotor e, assim, avaliar as possíveis configurações do sistema rotativo para uma determinada demanda de operação.
\end{abstract}

\section{Palavras-chave:}

Dinâmica de Rotores, Mancal Hidrodinâmico, Squeeze Film Damper.

\section{Introdução}

As atuais máquinas rotativas são sistemas extremamente complexos e com grande diversidade de aplicações. Durante sua operação, um dos problemas mais comuns que afeta essas máquinas está relacionado ao excesso de vibração. Assim, visto que os efeitos das vibrações podem ser bastante prejudiciais, evitá-las ou reduzi-las representa um ponto de grande interesse e importância nas mais diversas aplicações de engenharia. Além dos mancais hidrodinâmicos, os amortecedores do tipo "squeeze film" representa também uma boa alternativa para melhorar o desempenho do sistema. Os amortecedores do tipo "squeeze film" são componentes essenciais para máquinas rotativas que operam em altas velocidades, pois apresentam as vantagens de dissipar vibrações e isolar componentes estruturais, assim como aumentar a estabilidade dinâmica.

O presente projeto de pesquisa teve por objetivo introduzir o aluno Francisco Nogueira Saldanha Franco em atividades científicas, a partir da aplicação dos conhecimentos adquiridos nas disciplinas de Dinâmica, Vibrações e Métodos Numéricos (em especial MEF) em um problema prático, que, neste caso, refere-se a análise dinâmica de sistemas rotativos avaliando o comportamento dinâmico e o limiar de estabilidade de rotores, composto por diferentes tipos de mancais e amortecedores do tipo "squeeze film"

\section{Resultados e Discussão}

Para este trabalho foi utilizado um rotor conhecido como Rotor de Laval, Composto por um eixo, sustentado em suas duas extremidades e possuindo uma massa concentrada em forma de disco, em seu centro geométrico. Com o sistema modelado completamente, é possível analisar seu comportamento dinâmico no domínio do tempo e no campo da frequência. No campo da frequência, uma das análises é feita através da
Função em Resposta ao desbalanceamento, que mostra a amplitude da resposta em função da frequência de trabalho do rotor.

A outra análise na frequência foi feita através do diagrama de Campbell, um gráfico que mapeia as frequências naturais do sistema em função das frequências de funcionamento do rotor. O diagrama é obtido através do cálculo dos autovalores do sistema, e é utilizado para prever as zonas de ressonância do sistema. A partir deste resultado é possível calcular os coeficientes de amortecimento do sistema, respectivos a cada modo de vibração. Quando um coeficiente se mostra, matematicamente negativo, significa que 0 sistema se torna instável, determinando seu limiar de funcionamento.

\section{Conclusão}

Portanto, foi possível perceber a grande influência da sustentação do eixo no seu funcionamento, e no caso de mancais hidrodinâmicos e de amortecedores do tipo 'squeeze film'. Bem como, foi possível definir como seu projeto deve ser modificado, se necessário, em vista da faixa de trabalho que o rotor será requisitado, aumentando sua faixa de instabilidade através da implementação de amortecedores do tipo 'squeeze film', para impedir o mesmo de atingir zonas de instabilidade e ressonância, que podem gerar falhas.

\section{Agradecimentos}

Gostaria de agradecer ao Prof. Dr. Gregory Bregion Daniel, pela orientação durante este projeto, e pela oportunidade como um todo.

\footnotetext{
Krämer, E., Dynamics of rotors and foundations. Springer Science \& Business Media, 2013

${ }^{2}$ Daniel, G. B.; Machado, T. H.; Cavalca, K. L., Investigation on the influence of the cavitation boundaries on the dynamic behavior of planar mechanical systems with hydrodynamic bearings. Mechanism and Machine Theory, v. 99, p. 19-36, 2016.
} 